\title{
Erratum to: Identification of novel rice low phytic acid mutations via TILLING by sequencing
}

\author{
Sang-Ic Kim • Thomas H. Tai
}

Published online: 27 November 2014

(C) Springer Science+Business Media Dordrecht 2014

\section{Erratum to: Mol Breeding DOI 10.1007/s11032-014-0127-y}

In Table 3, there were three errors in the values reported for the "100-grain weight" column, which affect three parts of the manuscript. The authors apologize to the readers of Molecular Breeding for all inconveniences caused by these mistakes. The paper should be modified as follows:

1. In Abstract section, the sentence starting with "Evaluation of these lines..." should read as "Evaluation of these lines indicates that one of the ITPK mutants (46\% $\mathrm{InsP}_{6}$ reduction) and one of the MRP mutants are similar to wild-type plants in seed weight, germination, and seedling growth".

The online version of the original article can be found under doi:10.1007/s11032-014-0127-y.

\section{S.-I. Kim · T. H. Tai}

Department of Plant Sciences, University of California,

Davis, CA 95616, USA

Present Address:

S.-I. Kim

Dupont Crop Protection, Stine Haskell Research Center,

Newark, DE 19711, USA

T. H. Tai $(\bowtie)$

USDA-ARS Crops Pathology and Genetics Research

Unit, Davis, CA 95616, USA

e-mail: Thomas.Tai@ars.usda.gov
2. In Results section, under the heading "Grain weight, germination, and seedling growth of lpa mutants", the first two sentences should read as "Although none of the homozygous lpa mutants exhibited obvious developmental defects, the IPTK splice mutant and the A1427T MRP mutant did show a significant reduction in grain weight (Table 3). Compared to wild type, the IPTK splicing site mutant and the A1427T MRP mutant had a 5 and $15 \%$ reduction in 100-grain weight, respectively".

3. In Discussion, the sentence starting with "In this study, two severe lpa mutants...." should read as "In this study, two severe lpa mutants (ITPK splicing site and OsMIK) showed significant delays in germination and seedling growth". 
Table 3 Comparison of seed dry weight and phosphorus contents of rice mutants and wild-type (Nipponbare)

\begin{tabular}{|c|c|c|c|c|c|c|}
\hline \multirow[t]{2}{*}{ Gene } & \multirow[t]{2}{*}{ Mutant line } & \multirow[t]{2}{*}{100 -grain weight $(\mathrm{g})^{\mathrm{a}}$} & \multicolumn{3}{|c|}{$P$ contents $\left(\mathrm{mg} \mathrm{g}^{-1}\right.$ seed $)$} & \multirow{2}{*}{$\begin{array}{l}\text { InsP }_{6} \\
\text { reduction }\end{array}$} \\
\hline & & & $\mathrm{InsP}_{6}^{\mathrm{b}}$ & $\mathrm{Pi}^{\mathrm{b}}$ & Total $\mathrm{P}^{\mathrm{b}}$ & \\
\hline Wild type & Nipponbare & $2.37 \pm 0.02$ & $2.55 \pm 0.18$ & $0.53 \pm 0.15$ & $3.30 \pm 0.11$ & - \\
\hline OsMIK $(\mathrm{Os} 03 \mathrm{~g} 5276)^{\dagger}$ & Nonsense & $2.35 \pm 0.05$ & $0.65 \pm 0.21^{*}$ & $2.55 \pm 0.33^{*}$ & $3.03 \pm 0.51$ & $74 \%$ \\
\hline \multirow[t]{2}{*}{ ITPK (Os09g34300) } & Splice & $2.27 \pm 0.03 *$ & $0.82 \pm 0.40^{*}$ & $1.88 \pm 0.21^{*}$ & $3.25 \pm 0.21$ & $68 \%$ \\
\hline & Substitution (P522L) & $2.30 \pm 0.14$ & $1.38 \pm 0.65^{*}$ & $1.75 \pm 0.50^{*}$ & $3.31 \pm 0.78$ & $46 \%$ \\
\hline \multirow[t]{2}{*}{ MRP (Os03g04920) } & Substitution (L733F) & $2.39 \pm 0.08$ & $1.79 \pm 0.69 *$ & $1.25 \pm 0.33^{*}$ & $3.55 \pm 1.11$ & $30 \%$ \\
\hline & Substitution (A1427T) & $2.02 \pm 0.07 * *$ & $2.04 \pm 0.78 *$ & $1.05 \pm 0.32 *$ & $3.44 \pm 0.51$ & $20 \%$ \\
\hline
\end{tabular}

Mutant line: Nonsense mutation, Splice; splicing site altered, Substitution (amino acid substitution and position in peptide)

All values are means and standard deviation from three independent assays

*, ** Significant difference from wild type by a Student's $t$ test at the level of $P=0.05$ and $P=0.01$, respectively

$\dagger$ lpa control (Kim et al. 2008b)

a 100-grain weight was measured from manually counted 100 grains from three homozygous lpa mutants

b Total $\mathrm{P}$, phytic acid $\mathrm{P}$, and inorganic $\mathrm{P}$ are expressed as phosphorus (atomic weight $P=31$ ) concentration to facilitate comparison 